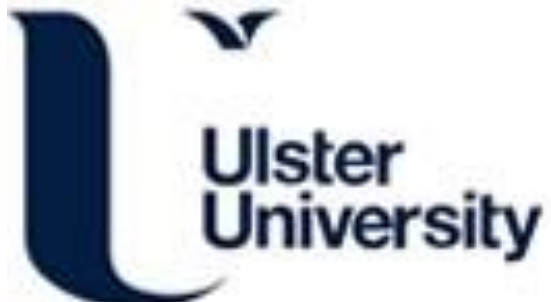

\section{Predicting golf ball launch characteristics using iron clubhead presentation variables and the influence of mishits}

Corke, T. W., Betzler, N. F., Wallace, E. S., \& Otto, S. R. (2021). Predicting golf ball launch characteristics using iron clubhead presentation variables and the influence of mishits. Proceedings of the Institution of Mechanical Engineers, Part P: Journal of Sports Engineering and Technology. https://doi.org/10.1177/1754337120987857

Link to publication record in Ulster University Research Portal

\section{Published in:}

Proceedings of the Institution of Mechanical Engineers, Part P: Journal of Sports Engineering and Technology

\section{Publication Status:}

Published online: 17/01/2021

DOI:

$10.1177 / 1754337120987857$

\section{Document Version}

Author Accepted version

\section{General rights}

Copyright for the publications made accessible via Ulster University's Research Portal is retained by the author(s) and / or other copyright owners and it is a condition of accessing these publications that users recognise and abide by the legal requirements associated with these rights.

\section{Take down policy}

The Research Portal is Ulster University's institutional repository that provides access to Ulster's research outputs. Every effort has been made to ensure that content in the Research Portal does not infringe any person's rights, or applicable UK laws. If you discover content in the Research Portal that you believe breaches copyright or violates any law, please contact pure-support@ulster.ac.uk. 


\title{
Predicting golf ball launch characteristics using iron clubhead presentation variables and the influence of mishits
}

\author{
Tom W Corke, Nils F Betzler, Eric S Wallace and Steve R Otto
}

\section{Abstract}

In golf, it is well understood that the interaction between the clubhead and ball determines the initial ball launch conditions. Specific knowledge regarding these relationships for iron clubs, particularly when clubhead and turf interactions are considered, would be both novel and of benefit to practitioners. Linear regression analysis was used to determine relationships between selected clubhead presentation and shot outcome variables for a sample of 1127 '5-iron' shots hit from natural turf by 96 golfers. As expected, clubhead speed was the most significant predictor of ball speed, with obliquity of impact and eccentricity of the impact location making smaller, yet statistically significant contributions. Marginally 'fat' strikes, whereby the leading edge of the clubhead was only slightly beneath the ground at impact, appeared to have a lesser effect than expected in terms of ball speed. Effective loft was found to be the strongest predictor of vertical launch angle, whilst clubhead speed and spin loft had the greatest influence in the model for predicting total spin; inclusion of 'thin' strikes (i.e. those struck with the leading edge) appeared to create a non-linear element to these models and consequently overestimated the influence of vertical impact location in both cases. These findings suggest that determination of impact location, particularly for instances whereby ball contact is not wholly on the club face, is critical in research concerning irons.

Overall, this study makes an original contribution to the understanding of 5-iron shot outcomes based on clubhead presentation characteristics.

Keywords

golf, iron, multiple regression, impact, clubhead presentation, launch conditions 


\section{Introduction}

A better understanding of the relationships between the golfer's presentation of the clubhead to the ball and the resultant shot outcome has long been sought after by golf researchers and practitioners alike. Simulations of impacts between the golf club and ball can offer some insight, but lack generalisability, as these simulations omit the performance of the golfer. However, using statistical techniques to fit models to large samples of player data allows for assessing relationships between input and output measures by searching for correlated variables amongst player-generated data sets.

Williams and Sih [1] reported correlations of clubhead presentation variables for both drivers and irons, however they did not measure the resulting ball launch conditions. As such, the effect of clubhead presentation on ball flight could not be determined. Hocknell [2] investigated the relationships between clubhead delivery and launch conditions, focusing on the relationship between efficiency (coefficient of restitution) and impact speed and impact location. The effects were mostly studied using simulated swings or swings performed by a golf robot; no other relationships are reported from player testing except for scatter plots of impact positions. Tuxen [3] reported statistics examining the effect of loft and attack angle on vertical launch angle and spin rate. Sweeney et al. [4] used three-dimensional motion tracking techniques to measure clubhead presentation of driver shots for a group of 21 golfers. Stepwise multiple regression was used to enhance understanding of relationships between clubhead presentation and ball speed. They also highlighted how ball launch spin is influenced by the difference between club face angle and the clubhead direction of travel. This approach to spin generation is thought to more 
closely represent the angle of incidence, as reported in impact tests [e.g. 5], or 'obliquity' of the impact. A later study by Betzler et al. [6] employed a similar technique for tracking driver clubhead presentation, but utilised a higher sampling rate of $1000 \mathrm{~Hz}$, compared to $400 \mathrm{~Hz}$ used by Sweeney et al. [4]. A forward-stepwise regression method was employed and all shots from all participants were included ( 285 players, 15 trials each), in contrast to the player averaged data of Sweeney et al. [4]. Although many of the relationships observed by the two studies were similar, there were some subtle differences, especially in terms of relative contributions of different predictor variables; the larger sample size would however suggest that the results reported by Betzler et al. [6] should be considered more statistically robust.

There remains a dearth of research that attempts to examine ball launch conditions based on clubhead presentation variables specifically for 'iron' clubs. It is difficult to infer findings from driver studies when considering 'iron' clubs due to vast differences in clubhead geometry and construction. Furthermore, differences exist between the characteristics of shots performed with these two club types (irons are not always hit from a tee-peg), as well as the objectives of the shot (driver shots are often hit with the goal of achieving maximum distance, whereas this is not necessarily true for irons). Therefore, research is important to gain an understanding of shot determinants associated with clubhead presentation characteristics with irons, especially if the results are different from driver findings, ultimately leading to advanced knowledge for coaching and fitting practices. Thus, the aims of the present study were to investigate (i) the effects of 
'mishits' on shot outcome parameters and (ii) the relationships between iron clubhead presentation variables and shot outcome parameters.

\section{Methods}

\subsection{Experimental Design and Sample Group}

The bespoke method used in the study to instrument, track and process iron clubhead presentation is similar to that utilised for drivers by Betzler et al. [6] and has been described in detail by Corke et al. [7]. The method included the tracking of the height of an iron's leading edge around impact to indicate whether the club was likely to be in contact with the ground at impact (defined as a 'fat' strike), whether the impact was wholly on the club face ('good' strike), with the leading edge itself ('thin' strike), or at a point above the equator of the ball ('top' strike). An additional criterion was included that classified any strike as 'fat' if at least one of the three markers defining the leading edge was beneath the ground at impact. The effect of this impact classification (illustrated in Fig. 1) on shot outcome has not been previously discussed.

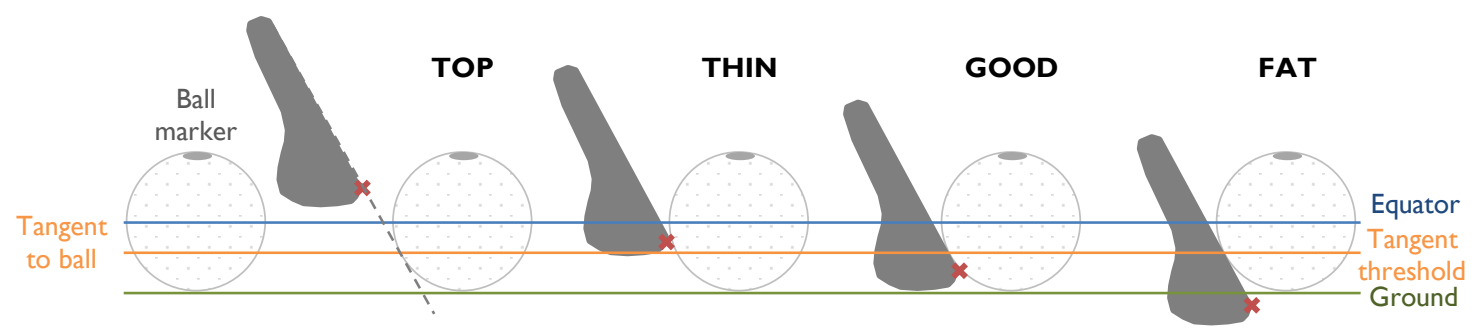

Figure 1: Strike classification based on leading edge height at impact 
A sample of 96 golfers performed 5-iron shots outdoors from natural turf. The turf represented the type and grass length that would typically be found within a tee box (i.e. it was cut short so that the ball rested on the ground level that was set when calibrating the Motion Capture system, and the soil was soft enough for the club to penetrate it in fat shots, rather than bouncing off it). Participants were required to be right-handed, over the age of 18 years, free from injury and have an active handicap. Ethical approval was granted from the institutional ethics committee prior to participant recruitment. After a self-selected warm-up, players were asked to hit 12 shots with each of two different 5iron clubs (one 'blade' and one 'cavity back') in alternating sets of six. Considering that the comparison of performance between club types has been addressed previously [9], for the sake of simplicity, only the results of the blade iron will be discussed herein. Club characteristics can be found in Table 1.

Table 1: Club characteristics for 'blade' 5-iron used in this study

\begin{tabular}{|c|c|c|c|c|c|c|c|c|c|c|c|c|c|c|}
\hline \multirow[t]{2}{*}{ Mass (g) } & \multirow{2}{*}{$\begin{array}{c}\text { Loft } \\
\left(^{\circ}\right)\end{array}$} & \multirow[t]{2}{*}{ Lie $\left({ }^{\circ}\right)$} & \multicolumn{3}{|c|}{$\begin{array}{c}C G_{\text {hosel }} \\
(\mathrm{cm})\end{array}$} & \multicolumn{3}{|c|}{$\begin{array}{c}C G_{\text {face }} \\
(\mathrm{cm})\end{array}$} & \multicolumn{3}{|c|}{$\begin{array}{c}\text { Ihosel } \\
\left(\mathrm{kg} \cdot \mathrm{cm}^{2}\right)\end{array}$} & \multicolumn{3}{|c|}{$\begin{array}{c}I_{\text {playing }} \\
\left(\mathrm{kg} \cdot \mathrm{cm}^{2}\right)\end{array}$} \\
\hline & & & $X_{h}$ & $Y_{h}$ & $Z_{h}$ & $X_{f}$ & $Y_{f}$ & $Z_{f}$ & $X_{h}$ & $Y_{h}$ & $Z_{h}$ & $X_{p}$ & $Y_{p}$ & $Z_{p}$ \\
\hline 252.4 & 25.7 & 60.4 & 3.73 & 0.83 & 6.69 & -0.18 & -0.40 & -1.00 & 12.6 & 17.6 & 5.4 & 1.2 & 2.8 & 1.8 \\
\hline
\end{tabular}

(CG: centre of gravity; I: moment of inertia)

Players were asked to hit 'full' 5-iron shots toward a predefined target flag at a rate that felt comfortable to them. Of the 96 participants, 79 were male and 17 were female. The mean $( \pm \mathrm{SD})$ age of the sample was $37.5( \pm 15.1)$ years. Playing handicaps of participants 
ranged from -5 ('plus 5' in golfing terminology) to 29 . The mean handicap ( \pm SD) of all 96 participants was $5.5( \pm 7.0)$, whilst means of male and female subgroups were 5.6 $( \pm 6.0)$ and $4.8( \pm 10.6)$, respectively.

\subsection{Instrumentation}

Three Oqus 300+ (Qualisys AB, Gothenburg, Sweden) cameras capturing at a frequency of $1000 \mathrm{~Hz}$ were used to track three opto-reflective tracking markers adhered to the clubhead prior to impact, as well as a reflective marker on the ball (see Fig. 1 in Corke et al. [10] for a schematic of the setup). Players were instructed to place the ball on the ground with the marker pointing vertically up. Consequently, half a ball diameter was subtracted from the ball marker position to locate the centre of the ball. The 3D calibration of the system was performed according to the recommendations of the manufacturer of the system. The ground level $(\mathrm{z}=0)$ was set by a calibration object resting on the floor. Average calibration residuals were $0.22 \mathrm{~mm}$. A calibration trial was used to define a plane relative to the tracking markers representing a virtual club face. The trajectory of this plane was extrapolated from the last pre-impact frame to determine a more precise, sub-frame impact time. The centre of gravity $(\mathrm{CG})$ of the clubhead, which was measured in a static test and also reconstructed virtually, provided a reference point for velocity-based measurements (clubhead speed, attack angle and clubhead path). The normal vector of the club face at the extrapolated impact time was used to determine face angle, effective loft and effective lie. Impact location was also measured by this clubhead tracking system, which has been validated as part of a previous publication [7]. A Trackman IIIe launch monitor was used to measure ball launch characteristics (ISG, 
Vedbæk, Denmark). Leach et al. [8] concluded that ball parameters measured with this device were in close agreement with an optical system and the device is suitable for golf research.

\subsection{Statistical Analysis}

The data were analysed using multiple regression with general linear models being created for ball speed, vertical launch angle, horizontal launch angle, total spin and spin axis. A simple forced entry method was used, as opposed to the stepwise methods employed in similar previous studies $[4,6]$, as it was believed that the predictors included in each model should be a decision made by the researcher, based on supporting theoretical evidence. This approach also avoided the risk of 'suppressor effects', i.e. the relative effect of a variable changing when other variables are first accounted for as noted by Corke [9]. All valid shots were included in the model, as opposed to player averages, as had been done in previous studies [4]. This was not thought to violate the assumption of correlated observations as the models reflected the physics governing the collision between ball and club. As such, which golfer was swinging the club was not considered relevant; the participants simply provided the necessary variance that enabled the regression analysis to be applied. The Durbin-Watson test statistic was nevertheless inspected as reassurance that this assumption had not been violated.

Shots identified as a 'shank' (i.e. the ball impacted the hosel of the club, as opposed to the club face) or a 'top' (i.e. the leading edge of the club face impacted the ball above its equator) [7] were removed from the sample, as it was thought that the resulting launch conditions would be governed by the geometry of the impact point on the club, as 
opposed to the systematic relationships that the study was trying to identify with regard to clubhead presentation. Furthermore, potential outliers were identified via visual inspection of the data, as well as running preliminary regression analyses. This permitted the calculation of leverage values and Cook's distances for each observation, which assisted in identification of any remaining potential outliers [11]. Of these potential outliers, those that could be attributed to erroneous measurement (e.g. changing light conditions causing poor marker tracking) or an external variable (e.g. something had distracted the participant) were excluded. A total of 25 shots were removed as part of this process, leaving a sample of 1127 shots. Additional assumptions, more specific to regression modelling, are those pertaining to heteroscedasticity and multi-colinearity. Partial plots and plots of standardised predictor values against standardised residual values were used for each model to assess the former, whilst variance inflation factors (VIF) exceeding 10 were considered to be indicators of potential issues with multicolinearity $[12,13]$, although the careful selection of predictor variables was thought to substantially reduce the associated risk.

\subsection{Definition of Predictor Variables}

All clubhead presentation measurements were evaluated at the sub-frame impact time. Conventions were such that to the right of (global y-direction) and above (global zdirection) the target line (global x-axis) were considered positive. The same applied to ball launch conditions, such that a ball launching above the horizontal or to the right of the target returned a positive value. The same applied to a spin axis tilted to the right of 
the global x-z plane. Clubhead presentation variables are defined below and illustrated in

Fig. 2.

- Clubhead speed: Speed of the clubhead's centre of gravity (CG) trajectory.

- $\quad$ Face angle: The angle between the club face normal vector and the global $x-$ axis in the global x-y plane.

- Clubhead path: The angle between the trajectory of the clubhead's CG and the global $\mathrm{x}$-axis in the global $\mathrm{x}$-y plane.

- $\quad$ Face-Path: Clubhead path subtracted from Face angle.

- $\quad$ Effective loft: The angle between the club face normal vector and the global $\mathrm{x}$-axis in the global $\mathrm{x}-\mathrm{z}$ plane.

- Attack angle: The angle between the trajectory of the clubhead's CG and the global $\mathrm{x}$-axis in the global $\mathrm{x}-\mathrm{z}$ plane.

- $\quad$ Spin loft: Attack angle subtracted from Effective loft.

- Impact location: Horizontal ( $\mathrm{x}_{\text {face}}$ ) and vertical $\left(\mathrm{y}_{\text {face }}\right.$ ) distances between the clubhead's CG location in the face coordinate system and the point of first contact with the ball.

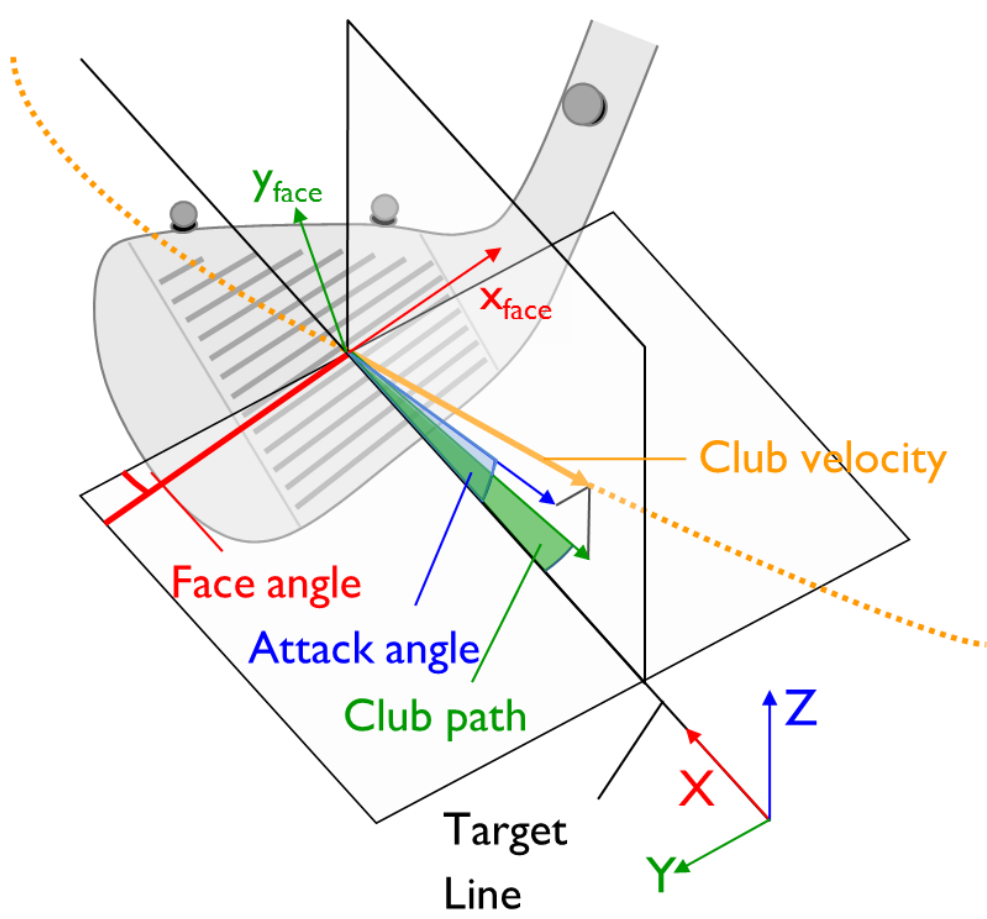


Figure 2: Representation of clubhead presentation variables in the context of the global coordinate system. (Reprinted from [7]).

\subsection{Selection of Predictor Variables}

- $\quad$ Ball speed: Greater clubhead speed was expected to result in greater ball speed, as has been found for drivers [6]. Similar to the study by Sweeney et al. [4], the combined measures spin loft (attack angle subtracted from effective loft) and face-path (clubhead path subtracted from face angle) were used to represent whether impacts were more or less oblique. Finally, impact location has been found to influence ball speed in both modelling $[17,18]$ and experimental studies [6]. Impact efficiency (ratio of ball speed to clubhead speed) has been shown to exhibit a quadratic relationship with impact location for iron shots [9], therefore impact location was squared to reflect this and enable inclusion in the linear model. Ball speed was expected to decrease as the squared distance of the impact location from the CG increased.

- Vertical launch angle: Effective loft and attack angle were each used as separate predictor variables as, in theory, either could affect launch angle independently [14]; both were expected to share a positive correlation with vertical launch angle, as has been seen for drivers previously $[4,6]$. Based on previous results $[4,6,9]$, vertical launch angle was expected to increase as impact occurs higher on the club face.

- Horizontal launch angle: Analogue to vertical launch angle, face angle, clubhead path and horizontal impact location were used as predictors. An open face angle or in-to-out clubhead path (i.e. pointing to the right of the target), or a horizontal impact location towards the toe of the club face, was expected to result in a horizontal launch angle to the right of the target line. Modelling of the club-ball impacts suggests that a given change in face angle will influence initial launch direction more than the same change in clubhead path [14].

- $\quad$ Total spin: The variables used for total spin were largely the same as were used for ball speed. Total spin was expected to increase with clubhead speed, as has been seen for drivers [6], and as impact became more oblique [4] (as quantified by spin loft and face-path). Both horizontal and vertical impact location have previously been shown to share a relationship with spin for drivers [17,18] and irons [9], although this is much more subtle in the case of the latter. Previous results show these relationships to be approximately linear.

- $\quad$ Spin axis: It was expected that any variable affecting total spin would also affect the relative components of backspin and sidespin imparted on the golf ball. Therefore, the same set of variables was used for the spin axis model as for total spin.

\section{Results and Discussion}


The following section summarises the effect of "mishits" on the regression models prior to the more general findings after appropriate removal of "mishits" from the dataset for some of the regression models.

\subsection{Non-Linear Relationships Arising from 'Thin' Strikes}

The necessary assumptions for the regression models were satisfied with the exception of two potential issues with non-linear relationships between predictor and dependent variables for vertical launch angle and total spin, each of which appeared to have a relationship that is not linear with vertical impact location for impacts low on the face. This relationship is illustrated in the partial plots in Figs. 3(a) and 4(a). The low impact position of the affected shots suggested that the deviation from linearity was caused by shots impacting the leading edge of the club. To test this theory, 'thin' shots were removed from the sample, and the regression models concerning the affected dependent variables were rebuilt using the remaining 1069 shots. The result of excluding 'thin' shots can be seen in partial plots taken from the revised models (Figs. 3(b) and 4(b)), in which the previous deviation from linearity appears to be greatly reduced. The exclusion of these shots also had a profound effect on the coefficients of the associated regression models (vertical launch angle and total spin), as can be seen by comparing the original results in the upper section of Table 2 with the revised models in the lower section. Excluding 'thin' strikes increased the overall variance explained by both models, as indicated by the respective coefficients of determination $\left(\mathrm{R}^{2}\right)$. The relative contribution of vertical impact location was considerably reduced for the vertical launch angle model, and further still in the case of total spin, to the extent where its contribution actually became non-significant. 


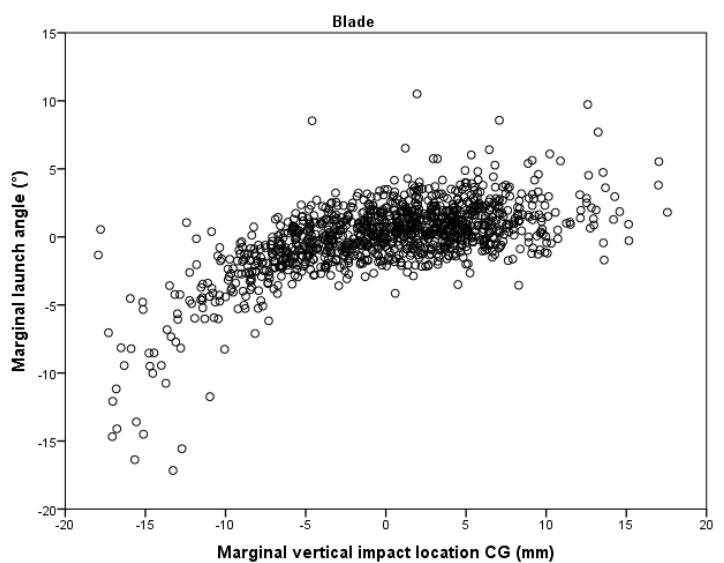

(a)

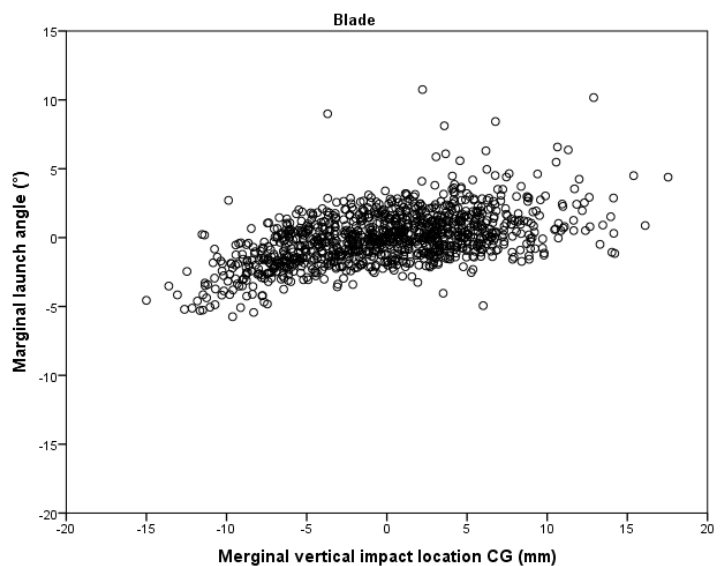

(b)

Figure 3: Partial plots illustrating the relationship between vertical impact location and vertical launch angle, after the effects of the other predictors (i.e. effective loft and attack angle) have been accounted for in both: (a) represents the plot taken from the original model, whilst (b) depicts the relationship following the exclusion of 'thin' shots.

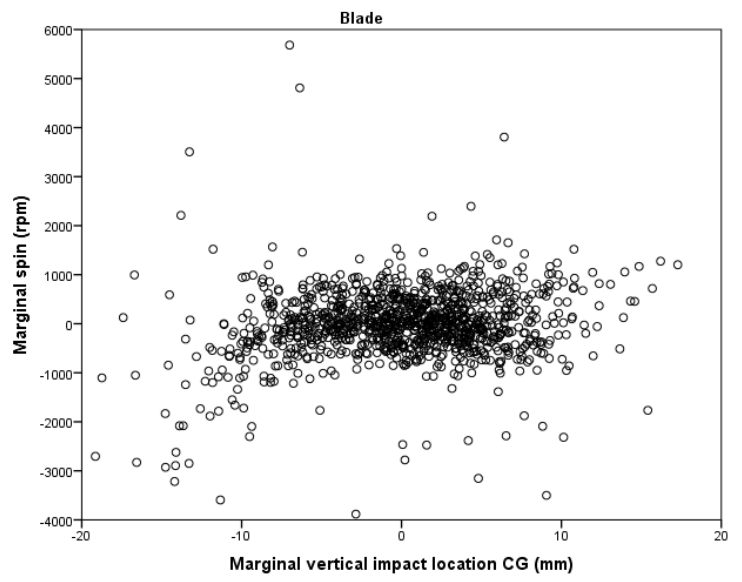

(a)

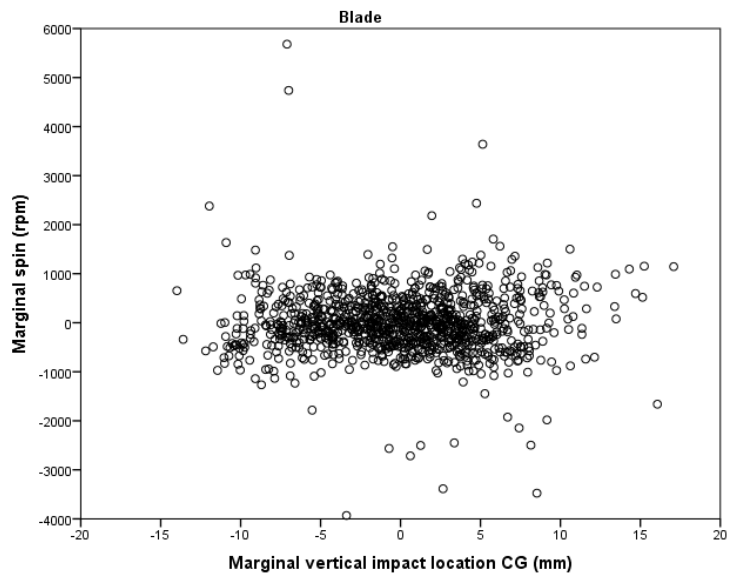

(b)

Figure 4: Partial plots illustrating the relationship between vertical impact location and total spin, after the effects of the other predictors (i.e. clubhead speed, face-path, spin loft and horizontal impact location) have been accounted for in both: (a) represents the plot taken from the original model, whilst (b) depicts the relationship following the exclusion of 'thin' shots. 


\subsection{Predicting Ball Launch Characteristics with Clubhead Presentation}

Table 2 summarises the results of the multiple regression models predicting ball launch characteristics from clubhead presentation. All factors that were included in the forced entry method were found to be significant, except for Spin loft as a predictor for Spin axis and Vertical impact location as a predictor for Total spin, after removing 'thin' shots. Table 3 summarises Durbin-Watson test statistics and Variance Inflation Factors for the model.

As expected, Clubhead speed was the most dominant predictor of Ball speed, followed by Impact location (squared), Face-path and Spin loft. However, it is worth noting that Spin loft would have been expected to have a larger effect on Clubhead speed if different types of irons with a range of loft angles were included in the study. 
Table 2: Beta values (b), standard error of the beta $\left(\mathrm{SE}_{\mathrm{b}}\right)$, standardised beta values $(\beta)$ and semi-partial correlations (sr) for the multiple regression models predicting ball launch characteristics (rows) with clubhead presentation variables (columns).

\begin{tabular}{|c|c|c|c|c|c|c|c|c|c|c|c|c|c|c|}
\hline & & \multirow{2}{*}{ Constant } & \multirow{2}{*}{$\begin{array}{l}\text { Clubhead } \\
\text { speed (mph) }\end{array}$} & \multirow{2}{*}{$\begin{array}{l}\text { Face } \\
\text { angle }\end{array}$} & \multirow{2}{*}{$\begin{array}{l}\text { Clubhead } \\
\text { path }\end{array}$} & \multirow{2}{*}{$\begin{array}{l}\text { Face- } \\
\text { path }\end{array}$} & \multirow{2}{*}{$\begin{array}{l}\text { Effective } \\
\text { loft }\end{array}$} & \multirow{2}{*}{$\begin{array}{l}\text { Attack } \\
\text { angle }\end{array}$} & \multirow{2}{*}{ Spin loft } & \multicolumn{2}{|c|}{ Impact Location (mm) } & \multicolumn{2}{|c|}{ Impact Location ${ }^{2}\left(\mathrm{~mm}^{2}\right)$} & \multirow{2}{*}{$\begin{array}{l}\text { adj. } \\
R^{2}\end{array}$} \\
\hline & & & & & & & & & & Horizontal & Vertical & Horizontal & Vertical & \\
\hline \multirow{4}{*}{$\begin{array}{l}\text { Ball speed } \\
\text { (mph) }\end{array}$} & $b$ & -7.09 & 1.31 & & & -0.59 & & & 0.52 & & & -0.015 & -0.016 & \multirow{4}{*}{.869} \\
\hline & $S E_{b}$ & 2.01 & 0.02 & & & 0.06 & & & 0.07 & & & 0.001 & 0.001 & \\
\hline & $B$ & - & .827 & & & -.142 & & & .110 & & & -.206 & -.143 & \\
\hline & $s r$ & - & .763 & & & -.103 & & & .080 & & & -.202 & -.136 & \\
\hline \multirow{4}{*}{$\begin{array}{l}\text { Vertical } \\
\text { launch } \\
\text { angle }\end{array}$} & $b$ & 6.17 & & & & & 0.50 & 0.43 & & & 0.275 & & & \multirow{4}{*}{.635} \\
\hline & $S E_{b}$ & 0.50 & & & & & 0.02 & 0.03 & & & 0.010 & & & \\
\hline & B & - & & & & & .532 & .325 & & & .550 & & & \\
\hline & $s r$ & - & & & & & .397 & .264 & & & .491 & & & \\
\hline \multirow{4}{*}{$\begin{array}{l}\text { Horizontal } \\
\text { launch } \\
\text { angle }\end{array}$} & $b$ & -0.58 & & 0.59 & 0.28 & & & & & -0.050 & & & & \multirow{4}{*}{.860} \\
\hline & $S E_{b}$ & 0.04 & & 0.01 & 0.01 & & & & & 0.004 & & & & \\
\hline & $B$ & - & & .657 & .375 & & & & & .152 & & & & \\
\hline & $s r$ & - & & .478 & .282 & & & & & -.144 & & & & \\
\hline \multirow{4}{*}{$\begin{array}{l}\text { Total spin } \\
\text { (rpm) }\end{array}$} & $b$ & -3077 & 55.7 & & & 48.0 & & & 152.0 & -7.6 & 23.1 & & & \multirow{4}{*}{.471} \\
\hline & $S E_{b}$ & 293 & 2.7 & & & 9.0 & & & 10.7 & 2.4 & 4.0 & & & \\
\hline & $B$ & - & .489 & & & .161 & & & .450 & -.074 & .149 & & & \\
\hline & $s r$ & - & .455 & & & .115 & & & .308 & -.068 & .126 & & & \\
\hline \multirow{4}{*}{ Spin axis } & $b$ & -0.83 & 0.051 & & & 1.54 & & & -0.11 & -.011 & -0.27 & & & \multirow{4}{*}{.592} \\
\hline & $S E_{b}$ & 1.76 & 0.016 & & & 0.05 & & & 0.06 & 0.01 & 0.02 & & & \\
\hline & $b$ & - & .066 & & & .769 & & & -.050 & -.166 & -.262 & & & \\
\hline & $s r$ & - & .062 & & & .548 & & & -.034 & -.151 & -.222 & & & \\
\hline \multirow{4}{*}{$\begin{array}{l}\text { Vertical } \\
\text { launch } \\
\text { angle* }\end{array}$} & $b$ & 6.05 & & & & & 0.49 & 0.46 & & & 0.182 & & & \multirow{4}{*}{.706} \\
\hline & $S E_{b}$ & 0.42 & & & & & 0.02 & 0.02 & & & 0.009 & & & \\
\hline & $B$ & - & & & & & .571 & .396 & & & .359 & & & \\
\hline & $s r$ & - & & & & & .434 & .322 & & & .327 & & & \\
\hline \multirow{4}{*}{$\begin{array}{l}\text { Total spin } \\
(\text { rpm)* }\end{array}$} & $b$ & -2777 & 53.7 & & & 52.3 & & & 142.3 & -6.7 & 1.0 & & & \multirow{4}{*}{.512} \\
\hline & $S E_{b}$ & 274 & 2.5 & & & 8.5 & & & 10.0 & 2.3 & 4.1 & & & \\
\hline & $B$ & - & .487 & & & .181 & & & .433 & -.068 & .006 & & & \\
\hline & $s r$ & - & .452 & & & .132 & & & .304 & -.062 & .005 & & & \\
\hline
\end{tabular}

Italic typeface indicates beta value not significantly different from zero ( $\mathrm{p}<.01)$. Asterisk $(*)$ indicates that 'thin' shots were omitted from the model. 
Table 3: Durbin-Watson test statistics and Variance Inflation Factors for the multiple regression models predicting ball launch characteristics with clubhead presentation variables.

\begin{tabular}{|c|c|c|c|c|c|c|c|c|c|c|c|c|}
\hline & \multirow{3}{*}{$\begin{array}{l}\text { Durbin- } \\
\text { Watson }\end{array}$} & \multicolumn{11}{|c|}{ Variance Inflation Factors } \\
\hline & & \multirow{2}{*}{$\begin{array}{l}\text { Clubhead } \\
\text { speed }\end{array}$} & \multirow[t]{2}{*}{ Face angle } & \multirow{2}{*}{$\begin{array}{l}\text { Clubhead } \\
\text { path }\end{array}$} & \multirow[t]{2}{*}{ Face-path } & \multirow[b]{2}{*}{$\begin{array}{l}\text { Effective } \\
\text { loft }\end{array}$} & \multirow[b]{2}{*}{$\begin{array}{l}\text { Attack } \\
\text { angle }\end{array}$} & \multirow[b]{2}{*}{ Spin loft } & \multicolumn{2}{|c|}{ Impact Location (mm) } & \multicolumn{2}{|c|}{ Impact Location ${ }^{2}\left(\mathrm{~mm}^{2}\right)$} \\
\hline & & & & & & & & & Horizontal & Vertical & Horizontal & Vertical \\
\hline Ball speed & 1.95 & 1.35 & & & 2.15 & & & 2.00 & & & 1.03 & 1.14 \\
\hline $\begin{array}{l}\text { Vertical } \\
\text { launch } \\
\text { angle }\end{array}$ & 1.97 & & & & & 1.74 & 1.45 & & & 1.25 & & \\
\hline $\begin{array}{l}\text { Horizontal } \\
\text { launch } \\
\text { angle }\end{array}$ & 2.06 & & 1.76 & 1.60 & & & & & 1.15 & & & \\
\hline Total spin & 1.94 & 1.32 & & & 2.20 & & & 2.18 & 1.24 & 1.36 & & \\
\hline Spin axis & 2.05 & 1.32 & & & 2.20 & & & 2.18 & 1.24 & 1.36 & & \\
\hline $\begin{array}{l}\text { Vertical } \\
\text { launch } \\
\text { angle* }\end{array}$ & 1.86 & & & & & 1.74 & 1.52 & & & 1.21 & & \\
\hline Total spin* & 1.92 & 1.16 & & & 1.89 & & & 2.04 & 1.16 & 1.311 & & \\
\hline
\end{tabular}

Asterisk (*) indicates that 'thin' shots were omitted from the model. 
As described in the previous section, the model for vertical launch angle was improved by removing 'thin' shots from the input data. Effective loft had the greatest influence over vertical launch angle, with attack angle and vertical impact location accounting for a lesser, but approximately equal proportion of the variance. The driver model by Betzler et al. [6] found that effective loft and vertical impact position were of approximately equal importance and explained the largest proportion of the variance in vertical launch angle; this greater influence of vertical impact location for drivers seems reasonable when comparing the convex club face of modern drivers with the flat face of iron clubs. In contrast, the results reported by Sweeney et al. [4] appeared to place greatest importance on attack angle ('club-head vertical velocity' as reported by the authors), whilst loft and vertical impact location offered additional significant contributions to their model.

The prediction of horizontal launch angle was dominated by face angle, although significant contributions to the model were also made by clubhead path and horizontal impact location. This largely agrees with driver studies, particularly that of Betzler et al. [6]. Sweeney et al. [4] also found face angle to contribute most to the prediction of horizontal launch angle; however, neither path, nor horizontal impact location, were found to account for any significant proportion of the remaining unexplained variance.

After removing 'thin' strikes from the model, clubhead speed contributed only marginally more than spin loft to the prediction of total spin. However, clubhead speed shared a more noticeably unique relationship with the dependent variable, as indicated by the 
relative semi-partial correlations (sr). Face-path was found to contribute a smaller, yet meaningful amount, whilst horizontal impact location only contributed a very small amount to the model. The contribution of vertical impact location was not found to be statistically significant. In contrast, the driver models generated by Betzler et al. [6] found vertical impact location to be the strongest predictor of total spin, followed closely by effective loft and attack angle (which were considered as separate variables), whilst clubhead speed was found to account for a lesser, yet apparently meaningful amount of the remaining unexplained variance. This may reflect fundamental differences between driver and iron shots: the greater loft of the iron clubhead and typically negative angle of attack will naturally transfer a greater proportion of the kinetic energy at a given clubhead speed tangentially to the ball, resulting in spin. Furthermore, the apparent importance of vertical impact location in predicting spin for driver shots [6] may be a result of differences in the depth of the clubhead's CG location and a phenomenon known as the 'gear effect', which is widely considered to play a much greater role in spin generation for driver shots than for irons $[17,18]$, due to the CG in irons being closer to the club face. Sweeney et al. [4] only reported the relationship between spin loft (different terminology was used by the authors) and backspin, which makes it difficult to compare to the current results or other driver studies. Furthermore, although the relationship reported by Sweeney et al. [4] was strong, the spin models were only based on eight player averages. Betzler et al. [6] did not report spin axis results.

\subsection{Influence of 'Fat' Strikes}

The process of classifying the nature of 'strike' between clubhead and ball based on the height of the leading edge at impact has been described previously [7]. It was expected 
that 'fat' strikes, also referred to as 'heavy' strikes by some golfers, could impede the overall distance of a shot in two ways: debris resulting from the clubhead's collision with the ground, hindering the transfer of kinetic energy from clubhead to ball, or contact with the ground resulting in a lower clubhead speed at impact relative to a trial in which the ball is struck before the ground.

Figures 5 and 6 illustrate the effect of both 'fat' and 'thin' shots on clubhead speed and impact efficiency respectively. Given that inter-player variation in clubhead speed is relatively large, it was necessary to normalise players' clubhead speeds to their session mean, which has been plotted against leading edge height (on which the majority of the impact classification process is based) in Fig. 5. The data suggests that for many 'fat' shots, clubhead speed is considerably reduced, although a considerable number of 'fat' shots had measured clubhead speeds equal to 'good' and 'thin' shots, for which no preimpact ground contact was thought to have occurred. It is acknowledged as a limitation of the clubhead tracking system that, unless the club has contacted the ground prior to the pre-impact frame, no deceleration would have been recorded. As a clubhead moving at $90 \mathrm{mph}\left(40.2 \mathrm{~m} . \mathrm{s}^{-}\right)$will travel approximately $4 \mathrm{~cm}$ between frames when capturing at $1000 \mathrm{~Hz}$, this would occur for late ground contact. This issue represents a worthwhile consideration when making decisions regarding sampling frequencies of future systems. Conversely, a very small number of 'good' strikes exhibited a considerable drop in clubhead speed. There are many factors that could cause an isolated swing to be much slower than a player's mean, however it is also possible that the clubhead collided with the ground prior to impact, but deflected in such a way that the leading edge was above 
the ground at impact. This is acknowledged as a shortcoming of considering only the impact frame, however it is reassuring at this stage that such potentially erroneous classification appears to occur very infrequently. In the present study, 3 of 712 'good' shots appear to have been misidentified in the current sample (i.e. those having lost in excess of $4 \mathrm{mph}$, see Fig. 5).

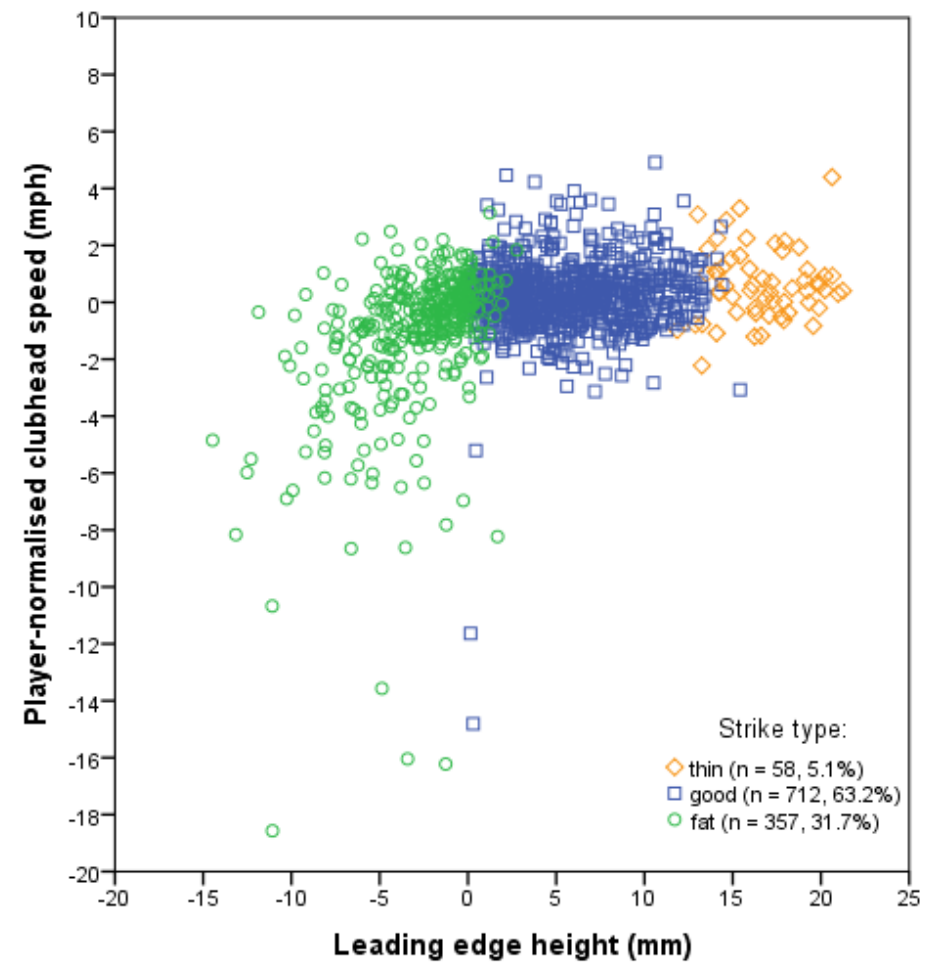

Figure 5: Clubhead speed (normalised to players' means) plotted against leading edge height at impact for strikes classified as 'thin', 'good' and 'fat'. Frequency and percentage breakdowns listed in legend (inset).

The effect of 'fat' strikes on efficiency (ratio of ball speed to clubhead speed) is more clearly observed than that its effect on clubhead speed alone, as efficiency tends to demonstrate much smaller inter-player variation. Figure 6 shows that strikes classified as 'good' generally produce the most effective transfer of clubhead speed to ball speed, and 
that efficiency appears to decrease as the height of the leading edge is located further beneath the level of the ground. Unexpectedly, a meaningful proportion of the shots classified as 'fat' appear to produce an impact efficiency that is equivalent to 'good' strikes. Misidentification of 'good' impacts as 'fat' is unlikely to be a result of measurement error, due to any error in tracking the height of the ball being 'one-tailed'. This is because the ball marker used to identify ball position can never be higher than the top most point of the ball, in which position the measured ball centre would match that of the true ball centre. Thus, slight misalignment of the ball position could cause a marginal 'fat' strike to be identified as 'good', but the opposite is unlikely to occur. Furthermore, regarding the caveat added to the effect of 'fat' strikes on clubhead speed, if it was in fact the case that the clubhead tracking system 'missed' reductions in clubhead speed occurring after the pre-impact frame, the reported efficiency would be greatly reduced due to clubhead speed being overestimated. Given that Fig. 6 shows a similar trend of marginal 'fat' shots demonstrating an efficiency comparable with 'good' shots, the frequency with which the system might 'miss' late deceleration of the clubhead is not a cause for concern at this stage. The fixed threshold and categorical nature of the shot classification may have resulted in shots being classified as 'fat' that were just a few millimetres below the threshold and, thus, not significantly slowed down because the tip of the grass is significantly softer than deeper ground layers. In conclusion, it appears that the negative effects associated with slightly 'fat' strikes (i.e. where the leading edge of the club is slightly or only partially beneath the ground at impact), in terms of both clubhead speed and impact efficiency, are perhaps not as severe as conventional wisdom might suggest. 


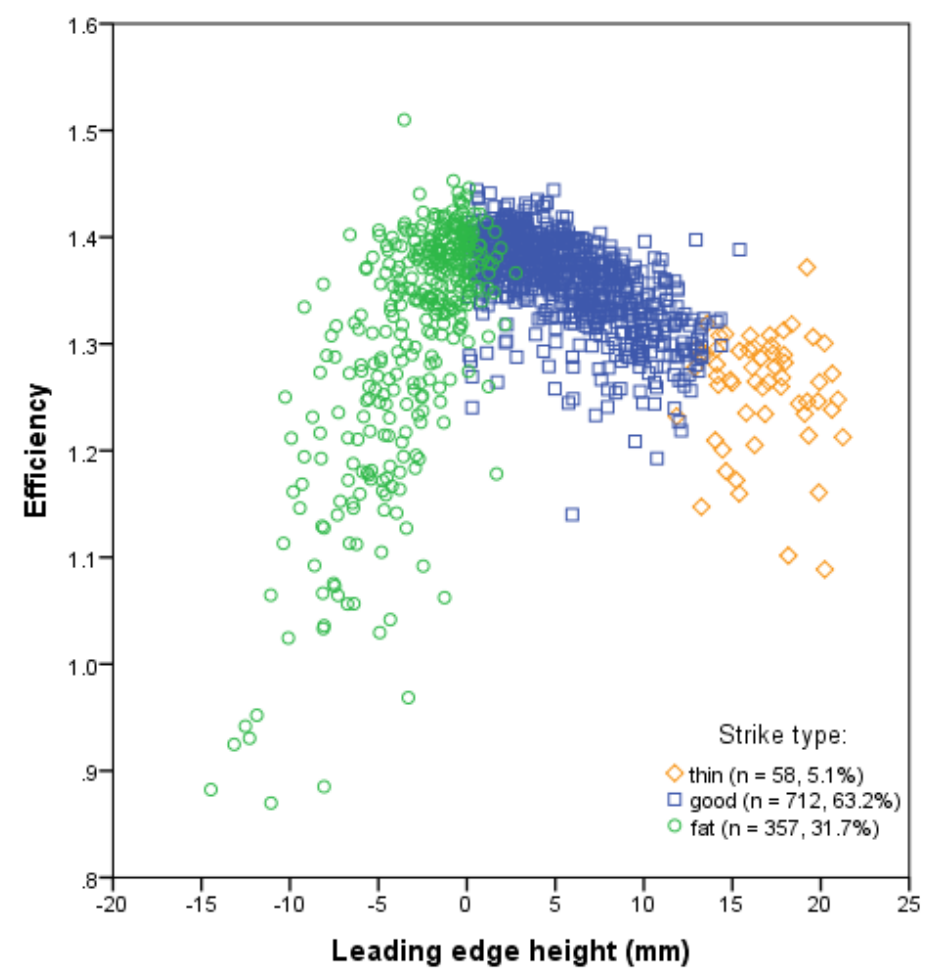

Figure 6: Efficiency plotted against leading edge height at impact for strikes classified as 'thin', 'good' and 'fat'. Frequency and percentage breakdowns listed in legend (inset).

\subsection{Strike Classification and Ability}

More skilled players have been shown to be more proficient strikers of the ball in driver studies, characterised either by a more consistent impact location [2] or a higher average efficiency [16], with similar results having been found for iron shots [9]. As such, it would be expected that the proportion of 'fat, 'good' and 'thin' shots might vary between handicap categories. Table 4 displays the frequencies of each strike type by handicap category. A Chi-square test revealed a statistically significant association between Category and the strike classification $\left(\chi^{2}=39.732, p<0.001\right.$, Cramér's $\left.V=0.131\right)$. 
'Good' strikes appear to be slightly more common amongst more skilled players, whilst 'thin' shots seem to be less common. These relationships agree with the idea that more skilled players exhibit greater ball striking proficiency, when classifying shots in this way. In contrast, however, the proportion of 'fat' strikes appeared to be greater for lower handicapped players. Considering that marginal 'fat' strikes seem to be less penal than conventional wisdom might suggest and that categorical analyses such as this do not account for the severity of a 'fat' strike, the meaningfulness of this apparent trend cannot be clearly determined at this point.

Table 4: Frequencies of strike classification by handicap category.

\begin{tabular}{clllll}
\hline \multicolumn{5}{c}{ Strike Classification } & \\
\cline { 2 - 5 } & Good & Fat & Thin & Total \\
\hline 1 & $425(63.8 \%)$ & $224(33.6 \%)$ & $17(2.6 \%)$ & $666(100.0 \%)$ \\
Category 2 & $202(63.1 \%)$ & $98(30.6 \%)$ & $20(6.3 \%)$ & $320(100.0 \%)$ \\
& $3+$ & $85(60.3 \%)$ & $35(24.8 \%)$ & $21(14.9 \%)$ & $141(100.0 \%)$ \\
Total & $712(63.2 \%)$ & $357(31.7 \%)$ & $58(5.1 \%)$ & $1127(100.0 \%)$ \\
\hline
\end{tabular}

Categories 1 (handicap < 6) and 2 (handicap 6-12) consistent with CONGU [15] handicap categorisation. Categories 3, 4 and 5 were combined to form Category 3+ (handicap >12) due to smaller numbers of observations in Categories 4 and 5. Percentages in parentheses are cumulative by row.

\section{Conclusion}

Regression analyses were successfully utilised to predict ball launch characteristics using selected clubhead presentation variables. Whilst many of these relationships were found to be consistent with those previously found for drivers, some meaningful differences were noted. One such difference is reduced influence of impact location on initial launch 
direction and spin for iron shots relative to drivers. This may be explained by differences in face geometry and the shallower centre of gravity location. Although impact location was found to be less critical to the outcome of iron shots than driver shots, it still appears to play an important role, and should therefore be included when modelling such impacts. Impact location also carries more pragmatic implications with regard to experimental research regarding iron shots; whilst marginally 'fat' shots appeared to cause a lesser penalty in terms of generating ball speed than conventional wisdom might suggest, 'thin' shots caused considerable issues with relationships which were not linear. As such, the ability to reliably detect 'thin' shots is vital to future experimental research concerning irons. Future work may look to expand on the present study by classifying shots with a continuous, rather than categorical (fat/good/thin) approach, and including a variety of different irons. Higher frame rates would further reduce uncertainty regarding ground contact between pre-impact sample and impact.

\section{References}

1. Williams KR and Sih BL. Changes in golf clubface orientation following impact with the ball. Sports Engineering 2002; 5: 65-80.

2. Hocknell A. High performance driver design: benefits for all golfers. In: Thain E (ed) Science and Golf IV: Proceedings of the World Scientific Congress of Golf. London: Routlege, 2002, pp.438-448.

3. Tuxen F. Optimization of Driving Distance - Importance of Determining the Attack Angle. In: Crews D and Lutz R (eds) Science and Golf V: Proceedings of the World Scientific Congress of Golf. Mesa: Energy in Motion, 2008, pp.469-476. 
4. Sweeney M, Mills P, Alderson J. and Elliott B. The influence of club-head kinematics on early ball flight characteristics in the golf drive. Sports Biomechanics 2013; 12: 247-258.

5. Arakawa K, Mada T, Komatsu H, Shimizu T, Satou, M, Takehara K. and Etoh, G. Dynamic Contact Behavior of a Golf Ball During an Oblique Impact. Experimental Mechanics 2006; 46: 691-697.

6. Betzler, NF, Monk, SA, Wallace ES and Otto SR. The relationships between driver clubhead presentation characteristics, ball launch conditions and golf shot outcomes. Proceedings of the Institution of Mechanical Engineers, Part P: Journal of Sports Engineering and Technology 2014; 228: 242-249.

7. Corke, TW, Betzler NF, Wallace ES, Otto SR. A novel system for tracking iron golf clubheads. Proceedings of the Institution of Mechanical Engineers Part P Journal of Sports Engineering and Technology. Epub ahead of print 13 August 2018. DOI: 10.1177/1754337118792798.

8. Leach, RJ, Forrester, SE, Mears, AC, Roberts JR. How valid and accurate are measurements of golf impact parameters obtained using commercially available radar and stereoscopic optical launch monitors? Measurement 2017; 112: 125-136. DOI: 10.1016/j.measurement.2017.08.009

9. Corke TW. Performance Differences Between Blade and Cavity Back Irons Within the Context of ShortTerm Player Variation. PhD thesis, Ulster University, UK, 2015.

10. Corke, TW, Betzler, NF, Wallace ES and Otto SR. Predicting golf ball launch characteristics using iron clubhead presentation variables and the influence of mishits. Journal of Sports Engineering and Technology 2020; in press.

11. Field A. Discovering Statistics Using IBM SPSS Statistics. 4th ed. London: SAGE Publications, 2013. 
12. Marquaridt DW. Generalized Inverses, Ridge Regression, Biased Linear Estimation, and Nonlinear Estimation. Technometrics 1970; 12: 591-612.

13. O'Brien RM. A Caution Regarding Rules of Thumb for Variance Inflation Factors. Quality \& Quantity 2007; 41: 673-690.

14. Miura K. Mapping Clubhead to Ball Impact and Estimating Trajectory. In: Thain E (ed) Science and Golf IV: Proceedings of the World Scientific Congress of Golf. London: Routlege, 2002, pp.490-500.

15. Council of National Golf Unions Limited. CONGU: Unified Handicapping System, https://www.englandgolf.org/wp-content/uploads/2018/08/2019-CONGU-Manual.pdf (2018, accessed 04 January 2019).

16. Betzler NF, Monk SA, Wallace ES, and Otto SR. Variability in clubhead presentation characteristics and ball impact location for golfers' drives. Journal of Sports Sciences 2012; 30: 439-448.

17. Cochran AJ and Stobbs J. Search for the Perfect Swing. Chicago, IL: Triumph Books, 1968.

18. Cross R. The polar moment of inertia of striking implements. Sports Technology 2010; 3: 215-219. 